\title{
Mensagens de educação matemática comunicadas no contexto de uma turma do Mestrado Profissional em Matemática em Rede Nacional ${ }^{1}$
}

\author{
Ilvanete dos Santos de Souza² \\ Jonei Cerqueira Barbosa ${ }^{3}$
}

\section{Resumo}

Neste artigo, o objetivo foi identificar e caracterizar que mensagens de educação matemática são comunicadas na prática pedagógica no contexto de uma turma do Mestrado Profissional em Matemática em Rede Nacional. Tratase de uma pesquisa qualitativa e os dados foram produzidos por meio de observação, entrevistas e documentos, à luz de constructos da teoria dos códigos de Basil Bernstein. Os resultados sugerem diferentes formas de seleção, sequenciamento e compassamento da prática pedagógica, além de uma variação no enquadramento, tendendo a mais forte ou mais fraco. As mensagens sobre educar matematicamente observadas reforçam o propósito previsto nos documentos oficiais do programa de que a "melhoria da prática pedagógica" acontece por meio do "domínio aprofundado de conteúdo matemático".

Palavras-chave: ProfMat; Prática Pedagógica; Mensagens; Educação Matemática.

\section{Mathematics education messages communicated in the context of a class of the Professional Master's in Mathematics on National Network}

\section{Abstract}

In this article, the objective was to identify and characterize that mathematical education messages are communicated in pedagogical practice in the context of a class of the Professional Master in Mathematics in the National Network. It is a qualitative research and the data were produced through observation, interviews and documents, in the light of constructs from Basil Bernstein's theory of codes. The results suggest different forms of selection, sequencing and compassion of the pedagogical practice, in addition to a variation in the framework, tending to be stronger or weaker. The messages about educating mathematically observed reinforce the purpose foreseen in the official documents of the program that the "improvement of the pedagogical practice" happens through the "in-depth mastery of mathematical content".

Keywords: ProfMat; Pedagogical Practice; Messages; Mathematical Education.

\section{Considerações iniciais}

Foi implementado no Brasil, a partir do ano de 2010, um programa de formação continuada de abrangência nacional, em nível de mestrado profissional, denominado Mestrado

\footnotetext{
${ }^{1}$ Este estudo compõe um dos artigos de uma tese organizada no formato multipaper. Uma versão preliminar deste estudo foi apresentada no XXII Encontro Brasileiro de Estudantes de Pós-Graduação em Educação Matemática- EBRAPEM, realizado no período de 01 a 03 de novembro de 2018, na cidade de Belo Horizonte, MG, na Faculdade de Educação da Universidade Federal de Minas Gerais (FaE/UFMG). No entanto, esta versão do estudo, teve trechos atualizados e ampliados.

2 Universidade Federal da Bahia, Salvador/BA. ilvanetess@gmail.com

${ }^{3}$ Universidade Federal da Bahia, Salvador/BA. joneicerqueira@gmail.com
} 
Profissional em Matemática em Rede Nacional - ProfMat (BRASIL, 2017). Nesta pesquisa, compreendemos a formação continuada "como aquela que ocorre após um curso de graduação" (NACARATO et al., 2016, p.335).

Esse programa pretende "atender prioritariamente professores ${ }^{4}$ de Matemática em exercício na educação básica" (BRASIL, 2017, p.4). E "que busquem aprimoramento da formação profissional, com ênfase no domínio aprofundado de conteúdo matemático relevante para sua docência" (BRASIL, 2017, p.4). O ProfMat, ao se constituir um programa de formação continuada proposto para professor de Matemática da educação básica, pode comunicar, tanto em sua elaboração quanto em sua execução, formas de educar matematicamente.

Neste estudo, entendemos que, em qualquer ambiente onde se ensina matemática, estáse educando matematicamente, o que pode se dar por meio de diversos processos. Nos moldes tradicionais, por exemplo, se educa matematicamente quando o professor ensina "mostrando" conceitos/exemplos, ao passo que o aluno aprende reproduzindo/realizando exercícios (SILVA, 1996). A essa forma, Alro e Skovsmose (2010) chamam de paradigma do exercício, o qual, por estabelecer padrões fechados de comunicação, tem sido contraposto de várias formas. Uma delas é a abordagem investigativa, a qual consiste na criação de cenários de investigação, abrange um conjunto de modos de ensinar que assumem formas variadas e tem, por isso, uma perspectiva de comunicação mais aberta (ALRO; SKOVSMOSE, 2010).

Assumimos aqui que, em toda formação de professor, é comunicada uma perspectiva sobre a educação matemática que pode ser praticada. É o caso da perspectiva de educação matemática comunicada, por exemplo, no ProfMat, que pode ser deslocada para sala de aula dos professores que participam desse programa, até porque uma das expectativas do ProfMat é de que a participação dos professores da educação básica cause um impacto na sua sala de aula (BRASIL, 2017). Em outras palavras, a partir da formação oferecida pelo programa aos professores, espera-se que eles possam mover o que foi "experienciado" para a sua prática docente na educação básica. Dessa forma, apresentamos, intuitivamente, a seguinte interrogação de pesquisa: qual a perspectiva sobre educar matematicamente veiculada no contexto de disciplinas de uma turma do ProfMat? Após a discussão dos constructos teóricos,

\footnotetext{
${ }^{4}$ Nesta pesquisa, denominamos de "professores" os acadêmicos que cursam o ProfMat e o "formador" aquele que leciona as disciplinas nesse programa.
}

Periódico Horizontes - USF - Itatiba, SP - Brasil - e021024 
reapresentaremos a interrogação de pesquisa em termos mais precisos.

A relevância dessa pesquisa consiste em apresentar insights sobre a perspectiva de educação matemática que se enuncia no contexto do ProfMat, refletindo sobre suas repercussões para a educação matemática que se pratica nas escolas.

Na próxima seção, mobilizaremos alguns conceitos da teoria dos Códigos de Bernstein $(2000,2003)$, tendo em vista ampliar a discussão sobre o objeto desta investigação, assim como para apresentar o objetivo em termos do quadro teórico.

\section{Mensagem da prática pedagógica na perspectiva bernsteiniana}

Os constructos teóricos que fundamentam este estudo estão ancorados em alguns conceitos da teoria de Basil Bernstein $(2000,2003)$. Um dos conceitos centrais diz respeito às formas de representação visíveis que comunicam alguma coisa, sejam elas expressas por meio de fala, escrita, de aspectos visuais, espaciais, e até mesmo na postura ou vestimenta do indivíduo participante da situação de comunicação. Tais representações transportam princípios de ordenamento e relação, os quais foram chamados por Bernstein (2000) de textos. O texto, por sua vez, é comunicado a partir de uma dada relação social.

Às relações sociais, cuja trama envolve alguém que ensina e alguém que aprende, Bernstein (2000) nomeou de prática pedagógica. Dessa forma, prática pedagógica é conceituada pelo autor de maneira ampla, como a relação social. Por exemplo, no âmbito de um curso de formação de professores, a prática pedagógica pode ser entendida como a relação estabelecida entre formadores e professores para ensinar e aprender determinados conteúdos.

Em um curso de formação de professores como o ProfMat, circulam textos que acabam por constituir uma determinada prática pedagógica. Podemos, então, falar de mensagem dessa prática pedagógica, em seu caráter coletivo e compartilhado, por meio de um processo de comunicação. A mensagem é o que a prática é. Isso quer dizer que a relação entre quem ensina e quem aprende comunica os significados legítimos sobre como se pode falar, comunicar, naquele contexto educacional (BERNSTEIN, 2000). Se considerarmos diferentes práticas pedagógicas, é coerente falar em mensagens, no plural, pois diferentes práticas acabam veiculando textos e significados diversos. 
Os conceitos de contexto comunicativo e código são usados por Bernstein (2000) para esclarecer a noção de mensagem. De acordo com o autor, o contexto comunicativo refere-se ao ambiente no qual a prática pedagógica acontece. Já o código pode ser compreendido como um princípio regulativo, tacitamente adquirido, o qual seleciona e integra os significados relevantes (para um determinado contexto), as formas de realização (textos produzidos) e os contextos evocadores (processos de formação continuada, por exemplo, em que há interação entre formadores e professores) (BERNSTEIN, 2003). O conceito de código compreende a comunicação legítima e a ilegítima; logo, pressupõe a existência de uma hierarquia entre as formas de comunicação e uma hierarquia no modo como são organizados a sua demarcação e os seus critérios (BERNSTEIN, 2003).

Por isso, a mensagem é um meio de socialização com o código, pois é no intermédio de sua realização que os participantes inferem sobre as regras contextuais. Nessa perspectiva, os textos que circulam no ProfMat também possuem uma mensagem sobre um certo modo de educar matematicamente. Por exemplo, a maneira como é organizada a aula pelo formador, a configuração de resolução dos exercícios, os formatos do uso ou não do livro-texto da disciplina comunicam mensagens da prática pedagógica sobre educar matematicamente.

A classificação do que se diz em um determinado contexto está estreitamente relacionada com as regras de reconhecimento do que pode ser dito nesse mesmo contexto. Sem isso, não é possível a produção de uma comunicação legítima (BERNSTEIN, 2000). Para Bernstein, portanto, o texto legítimo é compreendido como aquele reconhecido como apropriado para um contexto particular.

Bernstein também faz uso do conceito de enquadramento para definir as relações sociais nas categorias, isto é, a comunicação dentro delas, pois é o enquadramento que constitui a mensagem. Assim, inspirados no autor, inferimos que, no cenário de um curso de formação de professores, o enquadramento é mais forte quando os formadores têm maior controle da relação pedagógica; e é mais fraco quando os professores têm alguma forma de controle. A classificação e o enquadramento, juntos, definem o que poderá ser comunicado e a forma da comunicação legítima em determinado agrupamento social, ou seja, o que e o como das relações pedagógicas, mediando a produção e aquisição de códigos (BERNSTEIN, 2000). Entre os extremos de classificações fortes e fracas e de enquadramentos fortes e fracos, é possível existir diferentes modulações, que não são estanques. 
O enquadramento se refere à dimensão interacional. Dessa forma, ele é dado pelas relações de controle entre os indivíduos (por exemplo, formador-professor, professor-professor) e pode variar entre forte e fraco. Além disso, o autor em questão propõe que a variação no código acontece mediante as regras que fundamentam a prática pedagógica, a saber: as regras de seleção, as regras de sequenciamento, as regras de compassamento.

Segundo Bernstein (2000), as regras de seleção dizem respeito aos princípios que estabelecem a seleção do tema, do conteúdo ou dos dados de uma prática pedagógica. As regras de sequenciamento referem-se aos princípios que estabelecem uma progressão ou ordenamento da aprendizagem em/para uma dada atividade escolar, quer dizer, ordena o que vem antes e o que vem depois. Já as regras de compassamento dizem respeito aos princípios que estabelecem a velocidade ou uma taxa temporal relacionadas ao período necessário à aprendizagem e às regras de sequenciamento.

Depois de exposto o quadro teórico que nos permite dialogar com os dados desta pesquisa, reapresentamos nossa questão inicial: que mensagens da prática pedagógica sobre educar matematicamente são representadas em disciplinas ofertadas pelo ProfMat? Em outras palavras, nosso objetivo é o de identificar e caracterizar que mensagens de educação matemática são comunicadas na prática pedagógica no contexto de uma turma do ProfMat.

A seguir, discutiremos a literatura sobre a formação continuada de professores de Matemática e os constructos teóricos mobilizados no âmbito deste estudo.

\section{Formação continuada do professor de matemática}

No cenário educacional brasileiro, o tema formação de professores, seja inicial ou continuada, tem sido muito discutido. A formação dos professores configura-se objeto de várias políticas públicas que propõem um avanço na qualidade da formação e do trabalho docente (JARDILINO; OLIVERI, 2014).

Por ser um programa recente, ainda há poucos estudos a respeito do ProfMat (VICENTE; RESENDE, 2016; CALDATTO; PAVANELLO; FIORENTINI, 2016; BREDA; LIMA, 2017; FARIAS; VILELA, 2017; CALDATTO; FIORENTINI; PAVANELLO, 2018; SANTANA; GRILO; BARBOSA, 2018). Seus autores têm apontado algumas reflexões, como, por exemplo, sobre os documentos que 
compõem esse programa de formação continuada e como eles podem direcionar a prática pedagógica vivenciada nesse ambiente. Dentre os referidos estudos, destacamos o de Farias e Vilela (2017), cujo resultado aponta para uma visão de formação do professor de Matemática ancorada na Matemática acadêmica ${ }^{5}$, com ênfase para os conteúdos específicos, conduzindo para uma formação sólida do conteúdo matemático.

O estudo realizado por Farias e Vilela (2017) se propôs analisar a matriz curricular do ProfMat em três diferentes versões, compreendidas entre o período de 2010 e 2012. Como resultados, apontam que a formação do professor de Matemática está calcada em uma formação específica, a qual privilegia a Matemática acadêmica (maneira de fazer do matemático) em detrimento da Matemática escolar (modo de fazer do professor). Os autores ainda destacam que "a formação matemática aprofundada" é o objetivo principal do programa, pois se materializa por meio dos formadores que ministram as disciplinas no programa, bem como na seleção das disciplinas que constituem a matriz curricular, no processo de seleção e avaliação dos alunos, dentre outros aspectos.

Caldatto, Pavanello e Fiorentini (2016) corroboram com a visão de que há um distanciamento entre a prática pedagógica vivenciada no ProfMat e a prática pedagógica da escola da educação básica. Isso se dá porque a forma sofisticada como os conteúdos matemáticos específicos são trabalhados nesse programa durante a formação aproxima-se da Matemática acadêmica, ao tempo em que se distancia da Matemática escolar.

Embora as pesquisas supracitadas apontem que não há uma aproximação entre o que acontece no ProfMat e a realidade da sala de aula da educação básica, estes estudos não perscrutaram sobre o modo como essa prática acontece no contexto de um polo do ProfMat.

Esta lacuna na literatura nos conduziu à necessidade de olhar mais de perto essa nuance do referido programa, ou seja, sobre como sua prática acontece. Com tal propósito, nos enveredamos na busca de identificar e caracterizar que mensagens de educação matemática são comunicadas na prática pedagógica no contexto de uma turma do ProfMat. Sendo assim, apresentaremos, na próxima seção, o contexto e os participantes da pesquisa.

\footnotetext{
5 Entendemos matemática científica ou matemática acadêmica como aquela produzida pelos matemáticos profissionais, conforme David; Moreira; Tomaz (2013, p.45). Ou seja, a "Matemática acadêmica vista como um conjunto de práticas e saberes associados à constituição de um corpo científico de conhecimentos, conforme produzido pelos matemáticos profissionais e reconhecido socialmente como tal".
} 


\section{O contexto da pesquisa: ProfMat}

O ProfMat é formado por uma rede de instituições de Ensino Superior, no contexto da Universidade Aberta do Brasil (UAB)/Coordenação de Aperfeiçoamento Pessoal de Nível Superior (Capes), e coordenado pela Sociedade Brasileira de Matemática (SBM), com apoio do Instituto Nacional de Matemática Pura e Aplicada (Impa). A forma de ingresso nesse programa é regulamentada em edital e acontece por meio de seleções anuais, com a realização de Exame Nacional de Acesso (ENA) (BRASIL, 2017).

O ProfMat foi o primeiro mestrado profissional em rede recomendado pela CAPES. Atualmente se enquadra na modalidade semipresencial em rede, mas não é o único; inspirou o surgimento de outros programas de mestrado profissional, voltados ao ensino básico: Programa de Mestrado Profissional em Letras (ProfLetras) (2013); Programa de Mestrado Nacional em Ensino de Física (MNPEF) (2013); Programa de Mestrado Profissional em Artes (ProfArtes) (2014) e o Mestrado Profissional em Ensino de História (ProfHistória) (2014), dentre outros.

A matriz curricular do ProfMat é única, com a mesma ementa e bibliografia para todos os polos de abrangência do programa. É composta por nove disciplinas, sendo sete obrigatórias e duas eletivas, oferecidas ao longo de três anos e assim distribuídas:

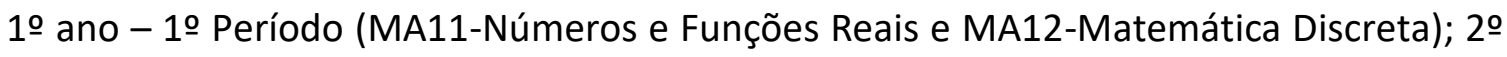
período (MA13- Geometria e MA 14- Aritmética);

2ำ ano - Verão (MA21-Resolução de Problemas) e 1ㅇ - 2 Período (Fundamentos de Cálculo; MA13- Geometria Analítica; Eletiva I e Eletiva II);

3ำ ano - Período de Verão (Finalização Dissertação de Mestrado).

As disciplinas do primeiro ano são consideradas básicas. Após a aprovação nessas quatro disciplinas, no período de verão, os professores cursam a disciplina MA21- Resoluções de Problemas, resultando em uma habilitação de acordo com as normas do programa, a realizar o Exame Nacional de Qualificação (ENQ). O exame é uma prova escrita, discursiva, e contempla os conteúdos das disciplinas básicas. Caso seja reprovado por duas vezes, o aluno é desvinculado do programa (BRASIL, 2017). Sendo aprovado, prossegue cursando as demais disciplinas; conclui o curso após defender publicamente o Trabalho de Conclusão de Curso, obtendo, assim, o título de Mestre em Matemática. 


\section{O ProfMat em uma turma de um polo: os participantes da pesquisa}

O ProfMat oferta turmas em todos os estados da federação, contando atualmente com 74 instituições associadas (BRASIL, 2017). A instituição que constitui o locus desta pesquisa localiza-se no nordeste brasileiro ${ }^{6}$ e oferece o curso desde sua primeira edição, em 2010, disponibilizando vinte vagas a cada edital de seleção.

Neste estudo, focamos apenas um polo e a turma que ingressou no semestre letivo 2017.1. Os colaboradores deste estudo são os professores e formadores das disciplinas observadas durante a pesquisa. Cabe destacar que dos 20 candidatos aprovados no Exame Nacional de Acesso (ENA), no referido semestre, frequentaram as disciplinas no primeiro período 14 professores. E no segundo período esse quantitativo foi reduzido para 12 professores.

Dos 14 acadêmicos, apenas uma é do sexo feminino; a média de idade da turma é de 34 anos. Todos são licenciados em Matemática; na ocasião apenas dois acadêmicos não estavam atuando como professores. Esses professores possuem uma carga horária mínima de trabalho de 40 horas e máxima de 60 horas semanais. Atuam há, no mínimo, dois anos e meio e, no máximo, há vinte anos como docentes na educação básica.

No ano de 2017 observamos todas as aulas das disciplinas oferecidas no semestre 2017.1 (MA11- Números e Funções reais e MA12- Matemática Discreta) e no semestre 2017.2 (MA13Geometria e MA14- Aritmética). Essas quatro disciplinas/turmas são aqui consideradas como quatro práticas e, portanto, figuram quatro relações pedagógicas entre quem ensina e quem aprende.

\section{Método}

Considerando o objetivo desta pesquisa, compreendeu-se a necessidade de uma pesquisa empírica por meio do método qualitativo, cuja intenção foi analisar mensagens pedagógicas sobre educação matemática, fenômeno eleito para descrição (CRESWELL, 2010).

A observação das aulas de quatro disciplinas básicas foi a estratégia principal de produção

\footnotetext{
${ }^{6}$ Mantemos a confidencialidade do nome da instituição com intuito de preservar a identidade dos participantes dessa pesquisa, inclusive como uma forma de garantir o acesso ao campo empírico.
}

Periódico Horizontes - USF - Itatiba, SP - Brasil - e021024 
de dados. Conforme Johnson e Christensen (2012), a observação é um procedimento que oportuniza produzir dados relevantes, possibilitando ao observador acompanhar as experiências desenvolvidas in loco pelos participantes no contexto natural.

No caso, a observação foi registrada por meio de um caderno de campo, o que viabilizou a identificação e caracterização das mensagens da prática pedagógica sobre educação matemática de uma turma em polo específico do ProfMat. Além disso, de forma subsidiária, realizamos ainda análise de documentos: Matriz curricular, Catálogo das disciplinas, Relatório de Avaliação do Programa e Livro-texto da Sociedade Brasileira de Matemática (SBM). Para caracterização do contexto, foram realizadas entrevistas individuais com os professores.

Para o registro dos dados produzidos, utilizamos: 1) o diário de campo, no qual registramos as observações referentes ao andamento do curso; os registros do formador no quadro e os episódios vinculados à produção de textos cujas mensagens versavam sobre educação matemática.

As categorias analíticas apresentadas na próxima seção foram estabelecidas a partir de alguns conceitos da teoria de Bernstein (2000; 2003). A análise e a discussão dos dados foram operacionalizadas à luz da literatura e da teoria aqui apresentada.

\section{Apresentação dos resultados}

Nesta seção, faremos uma caracterização de cada categoria de análise e, na sequência, apresentaremos os respectivos episódios/trechos do caderno de campo que ilustram aspectos relacionados às mensagens de educação matemática comunicadas a partir da prática pedagógica desenvolvida na turma que configura o corpus desta pesquisa.

Como dissemos, as categorias foram sistematizadas a partir de um diálogo com alguns conceitos da teoria de Bernstein (2000; 2003): 1) A seleção dos conteúdos do ProfMat; 2) O sequenciamento durante as aulas do ProfMat; 3) O compassamento da prática pedagógica. A seguir, apresentaremos cada uma delas, ilustrando-as com recortes da prática pedagógica observada. 


\section{A seleção dos conteúdos do ProfMat}

A definição dos conteúdos de uma disciplina é realizado de acordo com as regras de seleção empregadas na comunicação pedagógica. No entanto, esses princípios podem oscilar entre um enquadramento mais fraco e um enquadramento mais forte. Essa oscilação pode ocorrer de modo a favorecer ou estabelecer limites à comunicação pedagógica entre formador e professores na sala de aula.

Identificamos duas maneiras como os formadores organizam e selecionam os conteúdos que foram ministrados; são eles: a) fidelidade na seleção dos conteúdos; b) fidelidade relativa na seleção dos conteúdos.

Na primeira forma encontrada, fidelidade na seleção dos conteúdos, os formadores das disciplinas MA11- Números e Funções reais e MA12- Matemática Discreta apresentam os conteúdos de acordo com o Catálogo das disciplinas definido nacionalmente pelo ProfMat, ou seja, os conteúdos estudados são aqueles presentes no livro-texto, inclusive na mesma ordem em que são apresentados. Vale salientar que os professores têm acesso ao Catálogo de disciplinas por meio do portal do programa. O recorte abaixo exemplifica tal situação:

No primeiro dia (07/04/17) de aula da disciplina MA12- Matemática Discreta, a formadora escreveu a ementa na lousa com os seguintes conteúdos: Números naturais; Indução matemática; PA e PG; Recorrências lineares de 1aㅡ e 2aㅡordem; Matemática financeira; Sistema de amortização; Análise combinatória; Probabilidade; Médias e Princípio das gavetas. Ao concluir a escrita, a formadora anunciou: esse é o programa que temos que ver até o final da disciplina. E deu continuidade à aula, escrevendo na lousa os Axiomas de Peano (DIÁRIO DE CAMPO, 2017, p.101).

Ao compararmos a ementa apresentada acima pela formadora e a ementa do site do programa, percebemos que se trata dos mesmos conteúdos determinados pelo programa nacional. Dessa forma, podemos inferir que a mensagem sobre educação matemática presente nesse modo de selecionar os conteúdos pode estar vinculada à ideia de que o que está estabelecido no programa precisa ser trabalhado, ou seja, os programas podem ser percebidos como mandatórios.

A segunda forma de seleção dos conteúdos identificada foi a fidelidade relativa. Nesse 
modo de seleção, o formador da disciplina MA14 - Aritmética não seguiu os conteúdos tais como apresentados no livro-texto e na ementa, ou seja, o programa da disciplina foi atendido, porém contemplou os conceitos que ainda não tinham sido trabalhados nas duas disciplinas anteriores.

A ementa da disciplina MA14 - Aritmética não foi apresentada no primeiro encontro, e nem durante o curso. De acordo com o formador, não era necessário seguir a seleção sugerida no sumário do livro-texto, nem no Catálogo das disciplinas, pois alguns conteúdos foram estudados pelos professores na disciplina MA12- Matemática Discreta (DIÁRIO DE CAMPO, 2017, p.124).

Os dados sugerem que a mensagem sobre educação matemática comunicada na prática pedagógica, no contexto da disciplina MA14 - Aritmética, é da seleção dos conteúdos, considerando o que, na percepção do formador, já tinha sido estudado pelos professores, possibilitando uma flexibilidade no sentido de priorizar determinados conteúdos em detrimento de outros. Ou seja, na seleção dos conteúdos a serem ministrados, mesmo havendo um direcionamento presente na matriz curricular do curso e no sumário do livro-texto, o formador pôde reorganizá-los segundo um critério próprio, talvez baseado em experiências anteriores com a disciplina. Isso mostra uma flexibilidade de acordo com o contexto.

Tendo em vista os aspectos observados quanto à mensagem de educação matemática comunicada pela seleção dos conteúdos e pela prática pedagógica, observamos uma variação no enquadramento. Os conteúdos, nesse caso, são selecionados e organizados pelo programa, competindo, a priori, ao formador e aos professores desenvolverem o que está determinado. Em relação à última forma, percebemos um enquadramento mais fraco, pois o formador apresentou conteúdos que não estavam sugeridos nas orientações de seleção do conteúdo do programa.

\section{O sequenciamento durante as aulas do ProfMat}

O sequenciamento está relacionado à ordem das ações na prática pedagógica, ou seja, à divisão em etapas para a realização da disciplina. Trata-se de um princípio que regula o modo como os formadores, por exemplo, sequenciam suas aulas, os conteúdos, os procedimentos e estratégias, dentre outros aspectos. Segundo Bernstein (2000), a sequência é importante porque ela determina o modo como se dá a comunicação entre os textos, definindo o que precisa vir antes e depois. 
Nosso foco de análise nesta categoria recai, portanto, sobre qual mensagem de educação matemática é comunicada quanto ao modo como as aulas podem ser sequenciadas no âmbito do ensino de Matemática.

Identificamos modos semelhantes de organização e sequência das aulas por parte dos formadores; o que os diferenciava era a divisão temporal. Todos realizavam aula padrão, por meio da exposição de conceitos/demonstrações; exemplos e exercícios; aula de resolução de exercícios do livro-texto e aula mista (o formador explicava o conteúdo durante algumas aulas, por meio de conceitos/demonstrações e exemplos. Após conclusão de cada conteúdo, algumas aulas eram destinadas a apenas resolver algumas questões das listas de exercícios na lousa).

A aula padrão foi o primeiro modo de sequenciar a aula observado nas disciplinas MA12Matemática Discreta e MA14 - Aritmética. Consideramos como aula padrão o modo de sequenciar a aula expositiva, por meio de registros na lousa, seguindo esta ordem: primeiro registram-se os principais conceitos do conteúdo, explicando-os. Logo em seguida são apresentados exemplos de questões, respondidas pelo formador, com pouca participação da turma, que ilustram como esses conceitos podem ser apresentados. Para concluir a aula, são apresentadas algumas questões, as quais, por vezes, encontram-se no livro-texto da disciplina, ou são selecionadas pelo formador em outras fontes.

Há situações nas quais as questões que compõem os exercícios já foram contempladas no Exame Nacional de Qualificação. Para ilustrar a maneira como os formadores dessas disciplinas sequenciaram a aula padrão destinada à explicação de um novo conteúdo, apresentamos o trecho abaixo:

No segundo encontro (05/05/17) da disciplina MA12 - Matemática Discreta, o formador, de posse de folhas de ofício na qual constavam as anotações a serem registradas na lousa, iniciou o registro do conteúdo Princípio de Indução. A forma de registro na lousa se deu na seguinte sequência: Primeiro foi realizado o registro dos principais conceitos/demonstrações do conteúdo; logo após foram apresentados alguns exemplos (respondidos pelo formador), ilustrando as formas de resolução da questão. Para conclusão da aula expositiva, foram propostos alguns exercícios oriundos do livro-texto ou selecionados anteriormente pelo formador. Nesse momento, ele apresentou também a resolução das questões (DIÁRIO DE CAMPO, 2017, p.102-103). 
Os registros do diário de campo indicam que a mensagem de educação matemática comunicada nos textos produzidos em uma aula padrão pode estar vinculada à ideia de que há alguém (formador) que ensina - apenas por meio de conceitos pontuais, exposição de exemplos e demonstrações - e um outro (professor) que aprende, repetindo o que está sendo supostamente transmitido. Ou seja, é uma prática fortemente sequenciada em termos dos procedimentos de realização da aula. Esse tipo de aula ainda pode apresentar uma mensagem de educação matemática na qual o formador tende a determinar o que vem antes e o que vem depois, tanto em termos do conteúdo quanto dos procedimentos, tendendo a limitar a participação dos professores durante as aulas.

Já a segunda maneira de sequenciar a aula padrão foi identificada na disciplina MA11Números e Funções reais, e a nomeamos como aula de resolução de exercícios do livro-texto. Nesse modo de sequenciar a aula, os exercícios de um capítulo do livro-texto são previamente selecionados pelo formador e resolvidos na aula seguinte por duplas de professores. As formas de resolução geralmente são feitas por meio de registro na lousa da solução de uma questão por um integrante da dupla. Algumas duplas apresentam mais de um jeito de resolução para uma mesma questão. Essa forma de sequenciar a aula aconteceu durante alguns encontros da referida disciplina. Para explicitar essa maneira de sequenciar a aula, apresentamos o recorte a seguir:

O formador fez o envio de um e-mail para a turma com as orientações de como seria a dinâmica da aula do dia 14/04/17; o conteúdo a ser estudado seria Funções quadráticas. No e-mail constava, além das orientações, um cronograma organizado pelo formador com a seguinte estrutura: duas questões para cada dupla (geralmente eram sempre os mesmos professores); o número da questão e sua respectiva página no livro-texto, seguido do nome da dupla responsável por uma das oito apresentações programadas para aula seguinte. O comando dado pelo formador aos professores foi para resolverem a questão e apresentar a resolução na lousa, na aula seguinte. Todas as duplas presentes na aula realizaram a resolução das questões/demonstrações na lousa (o grupo cinco complementou a apresentação com uso do projetor de multimídia). Durante a aula, houve participação dos professores discutindo ou complementando as soluções apresentadas. Já o formador só fez intervenção durante a apresentação, quando solicitado pelo professor, ou ao final de cada apresentação das duplas, tecendo algumas considerações, com intuito de complementar o que foi apresentado. Ao final das apresentações, o formador concluiu o conteúdo por meio de aula expositiva participativa com uso do projetor de multimídia (DIÁRIO DE CAMPO, 2017, p.10). 
As notas do diário de campo indicam que a mensagem de educação matemática presente nessa segunda forma de sequenciar a aula, denominada de resolução de exercícios do livrotexto, pode denotar uma prática pedagógica em que o sequenciamento, embora seja previamente definido pelo formador, não especifica como devem ser os procedimentos do que deve ser explicitado antes ou depois na aula.

Na disciplina MA13- Geometria, também observamos o modo aula padrão. Nessa forma de sequenciar as aulas, o formador explicava todo o conteúdo, geralmente por meio de conceitos e exemplos. Assim que concluía a parte de exposição do conteúdo, destinava algumas aulas apenas à resolução de listas de exercícios por ele propostas. Como podemos perceber, a ordem é a mesma; entretanto, o que a diferenciou foi o tempo destinado à realização de cada etapa. Exemplificamos essa forma de sequenciar a aula através das seguintes observações registradas no diário de campo:

As aulas da disciplina MA13- Geometria - tiveram início no dia 25/08/17. Logo no primeiro encontro, o formador iniciou a aula com o seguinte conteúdo: Axiomas. A aula se configurou na seguinte sequência: o formador escrevia os conceitos/demonstrações dos conteúdos, utilizando exemplos para ilustrar o que estava sendo explicado. Durante esse período, o formador entregou algumas listas de exercícios para os professores irem respondendo em casa. Essa forma de organizar a aula só teve alteração no encontro do dia 20/10/17. Nesse encontro, o formador iniciou a aula sugerindo duas opções de como a aula poderia ser sequenciada. Na primeira opção, eles prosseguiriam com o conteúdo. Já a segunda opção foi começar a resolução dos exercícios na lousa. Após votação entre os professores presentes na aula, ficou decidido que a continuação do conteúdo de Axiomas seria em aulas extras e essa aula seria de resolução na lousa dos exercícios das listas entregues pelo professor. Algumas questões da lista 03 de exercícios foram respondidas. A forma de resolução acontecia na lousa por um professor voluntário, acompanhado do formador, que o auxiliava no processo de resolução (DIÁRIO DE CAMPO, 2017, p.35-56).

Com base nos registros do diário de campo, entendemos que a mensagem de educação matemática presente nessa prática sugere um sequenciamento em que o ensino e a aprendizagem da matemática perpassam os seguintes passos: antes o professor precisa conhecer todo o conteúdo, adquirindo uma "bagagem" de conceitos, fórmulas e demonstrações para só depois fazer uso do "repertório acumulado", tendo em vista a resolução dos exercícios propostos. Esse sequenciamento ainda aponta uma divisão em etapas para a realização das 
exigências solicitadas aos professores durante a prática pedagógica.

Embora exista uma variação do enquadramento entre forte e fraco, identificamos, nessa categoria, um sequenciamento forte, porém percebemos uma variação nesse enquadramento. Nas práticas observadas, o enquadramento é mais forte quando apenas o formador sequencia as aulas, os conteúdos, os procedimentos e estratégias de resolução dos exercícios. E o enquadramento é considerado apenas forte quando o formador sequencia as aulas e os conteúdos, mas os professores fazem uso de procedimento e estratégias próprias para a resolução dos exercícios.

De acordo com que foi apresentado, nota-se que os princípios reguladores do sequenciamento em uma aula de Matemática considerada padrão pressupõem que o formador trilhe os seguintes direcionamentos: i) copiar na lousa e explicar os principais conceitos, definições e demonstrações; ii) resolver questões como exemplo; iii) indicar lista de exercícios. Esse tipo de sequenciamento apresenta indícios de um enquadramento mais forte, o que pode indicar uma mensagem de educação matemática baseada na ideia de transmissão de conteúdo.

\section{O compassamento da prática pedagógica}

A regra de compassamento ou ritmagem da prática pedagógica é o ritmo esperado para a aquisição do código em um intervalo de tempo. Nesta categoria, apresentamos como se caracterizou a organização do tempo dentro do qual ocorreu o sequenciamento dos conteúdos, bem como que mensagem de educação matemática foi comunicada nesse processo.

Durante a observação das quatro disciplinas, e mediante os registros do diário de campo, identificamos dois modos de organização e distribuição do tempo/ritmo durante as aulas. São eles: a) Flexibilidade em relação ao tempo/ritmo para aquisição dos conteúdos; b) Inflexibilidade em relação ao tempo/ritmo para aquisição dos conteúdos.

Na primeira forma identificada, flexibilidade em relação ao tempo/ritmo para aquisição dos conteúdos, os formadores de três disciplinas - MA11- Números e Funções reais; MA 13Geometria e MA14- Aritmética - apresentaram propostas de atividades (seminário; explicação de conteúdo; resolução de exercícios, dentre outras) com tempo determinado. No entanto, quando os professores não conseguiam cumprir a tarefa de acordo com o tempo previsto ou no 
ritmo esperado, o formador permitia que outras aulas fossem destinadas à conclusão da atividade. O recorte abaixo exemplifica tal situação:

Na disciplina MA11- Número e Funções reais, foi definido, no primeiro encontro (07/04/18), como uma das atividades a ser realizada pela turma, um seminário do livro: História dos números e numerais ${ }^{7}$ (o seminário foi organizado com base nos temas de cada capítulo, compreendendo um total de onze capítulos, sendo que cada dupla de professores ficou responsável por apresentar um capítulo. A previsão de tempo definida para todas as apresentações foi de um encontro (quatro aulas) [...]. No entanto, o tempo determinado para essa atividade se estendeu por mais três encontros (doze aulas) [...]. Durante a realização desse seminário, houve espaços para discussão entre os professores e o formador sobre os conteúdos demandados pela atividade (DIÁRIO DE CAMPO, 2017, p.2-4).

Os dados sugerem uma comunicação de educação matemática, quanto aos princípios de compassamento, baseada na negociação do tempo, indicando uma consideração, por parte do formador, aos diferentes ritmos de aprendizagem, já que foi possível redimensionar o tempo destinado às atividades com vistas a atender aos diferentes perfis de desempenho.

Na segunda forma identificada, inflexibilidade em relação ao tempo/ritmo para aquisição dos conteúdos, a formadora da disciplina MA12- Matemática Discreta buscou cumprir o que havia determinado/planejado para cada encontro. Essa postura foi justificada pela extensa ementa a ser cumprida durante o semestre, além das exigências demandadas pelo Exame Nacional de Qualificação - ENQ.

No quarto encontro, da disciplina MA12- Matemática Discreta, realizado no dia 26/05/17, durante a aula sobre Progressões, no momento em que a formadora concluiu a explicação do tópico sobre Progressões Aritméticas e logo em seguida prosseguiu com o conteúdo, iniciando as explicações sobre Progressões Geométricas, um professor da turma fez a seguinte declaração em voz alta para a formadora: "Vamos parar!" E continuou: "Precisamos de tempo pra digerir todo esse somatório no quadro". A formadora continuou de costas escrevendo no quadro e respondeu: "Estou seguindo o script", referindo-se à necessidade de cumprir a ementa da disciplina (DIÁRIO DE CAMPO, 2017, p.104).

Os apontamentos do diário de campo supõem uma mensagem de educação matemática que considera que todos os professores possuem um único ritmo e que a aprendizagem acontece

\footnotetext{
${ }^{7}$ Livro: GUNDLACH, B. H. História dos números e numerais. São Paulo: Atual, 1992.
} 
ao mesmo tempo para todos. Essa unificação do tempo e ritmo para a aquisição dos conteúdos figura uma desconsideração da heterogeneidade dos professores participantes dessa prática pedagógica, ao trazer indícios de um enquadramento mais forte. Nesse tipo de compassamento, por exemplo, insurge uma tendência para redução nas formas de participação dos professores e consequente privilégio da fala do formador. Com essa vertente, o formador pode, por exemplo, sequenciar a aula de modo a definir o tempo exato destinado à realização da explicação de um conteúdo, de quantas questões podem ser respondidas nesse intervalo, ou ainda se as questões serão respondidas em aula ou extraclasse.

O programa tem um calendário unificado para todos os polos. Seguindo-o, na sala de aula, o formador fica limitado na forma como conduz sua prática pedagógica. Portanto, as regras de compassamento determinam o ritmo esperado para a aquisição dos conteúdos selecionados em um determinado espaço de tempo. Esses princípios podem influenciar no tempo e ritmo esperado para a aquisição do texto legítimo pelo professor.

Diante do exposto, no contexto observado, identificamos dois modos de sequenciar as aulas, como apontamos anteriormente: um flexível e o outro inflexível em relação ao tempo/ritmo para aquisição dos conteúdos. Tal como vimos, esses modos de lidar com o ritmo/tempo da turma comunicam diferentes mensagens de educação matemática. O primeiro caso sugere um reconhecimento de que a aprendizagem acontece em diferentes ritmos/tempos. No segundo, há uma valorização do tempo e uma suposta homogeneidade na aprendizagem, tendendo para uma maior regulação/limitação das oportunidades concedidas aos professores para exporem suas ideias ou dúvidas.

\section{Discussão dos resultados}

Nesta pesquisa, nosso objetivo foi identificar e caracterizar que mensagens de educação matemática são comunicadas na prática pedagógica no contexto de uma turma do ProfMat. Desse modo, reconhecemos que a dimensão interacional da prática pedagógica pode assumir características distintas, revelando modulações no enquadramento. Numa análise conjunta das quatro disciplinas em relação às três categorias que foram apresentadas anteriormente, notamos que existe certa variabilidade no enquadramento. Ou seja, as mensagens sobre educar 
matematicamente, na dimensão interacional, que se tornam visíveis a partir dos textos comunicados no ProfMat, variam.

Assim, observando as categorias supracitadas, notamos que as características das relações entre formador e professores, representadas no ProfMat, podem ser descritas por regras de seleção, regras de sequenciamento e regras de compassamento. Essas regras podem ter um enquadramento mais forte quando as decisões referentes a essa prática pedagógica estão exclusivamente centradas no formador, destituindo o professor da possibilidade de inferir sobre as decisões tomadas. Já quando essas regras variam para um enquadramento tendendo a mais fraco, percebe-se um compartilhamento nas decisões.

A primeira categoria - seleção dos conteúdos da prática pedagógica - apresenta dois modos distintos de o formador selecionar os conteúdos a serem ministrados na disciplina: a) fidelidade na seleção dos conteúdos; b) fidelidade relativa na seleção dos conteúdos.

Os dados apresentados nessa primeira categoria comunicam, ainda, uma mensagem de educação matemática cuja suposição é de que, quanto mais fidedigna é a seleção do conteúdo em relação à ementa do programa, o enquadramento tende a ser mais forte. No entanto, quando há a incorporação de outros conteúdos além daqueles prescritos pela ementa da disciplina, percebe-se um enquadramento tendendo a mais fraco.

Os dados apresentados na primeira categoria, referentes à fidelidade na seleção dos conteúdos, corroboram com os estudos desenvolvidos por Oliveira (2013), Souza (2013). Tais autores mostraram que o material didático (livro-texto, caderno de atividades dentre outros) de um programa de formação pode exercer um forte controle na seleção do conteúdo e na mensagem de educação matemática comunicada, principalmente quando o formador busca segui-lo de forma fidedigna, desconsiderando outros fatores que comparecem no processo pedagógico.

Dessa forma, mesmo a disciplina tendo a ementa e o material unificado no âmbito nacional, com conteúdos previstos para o Exame Nacional de Qualificação, isso não impõe uma regularidade nas formas de comunicação, ou seja, a maneira como cada polo realiza o texto pode ser diferente, mesmo havendo um limite ali, dado por certo controle vertical. No entanto, os princípios que estão regendo essa prática podem ser considerados comuns a qualquer turma que trabalhe com aquela disciplina, em qualquer polo; mas a forma como ela é realizada em cada 
turma pode ser única, entrevendo singularidade, pois a produção do texto vai se adequar ao contexto para ganhar legitimidade.

Com relação à segunda categoria - o sequenciamento da prática pedagógica durante as aulas - foi identificado um único modo: aula padrão. Essa estratégia comunica o modo como os formadores organizam e sequenciam suas aulas e como elas podem comportar diferentes mensagens sobre educação matemática. Nas aulas em que o sequenciamento tende para um enquadramento mais forte, a mensagem sobre educar matematicamente está centrada no ensino como transmissão. Tal vertente recai no que Alro e Skovsmose (2010) denominam de paradigma do exercício, o que significa dizer que, na aula padrão, geralmente o formador apresenta definições e conceitos, seguidos de exemplos que comportam técnicas matemáticas, as quais serão aplicadas pelos professores na resolução dos exercícios.

No entanto, quando o sequenciamento da aula tende para um enquadramento mais fraco, a mensagem de educar matematicamente sugere um compartilhamento de papéis durante a aprendizagem. Tal modulação da prática pedagógica pode favorecer, por exemplo, o que Alro e Skovsmose (2010) denomina de cenários de investigação. Os cenários de investigação possibilitam que as atividades de resolução de problemas se configurem como atividades investigativas, propondo que os professores elaborem suas próprias estratégias de resolução e defendam seus argumentos a respeito do tema estudado.

Já na terceira e última categoria - o compassamento da prática pedagógica - identificamos dois modos de compassamento: a) Flexibilidade em relação ao tempo/ritmo para aquisição dos conteúdos; b) Inflexibilidade em relação ao tempo/ritmo para aquisição dos conteúdos.

Essas formas distintas de compassar a aula influenciam diretamente nas mensagens comunicadas sobre educar matematicamente. Em outras palavras, quando o compassamento tende a um enquadramento mais forte, a mensagem sobre educar matematicamente considera que todos aprendem no mesmo ritmo e tempo. Já quando o compassamento tende a um enquadramento mais fraco, a mensagem sobre educar matematicamente indica que os tempos e ritmos de aprendizagem são distintos e singulares. Por mais que exista uma flexibilização no compassamento, no contexto de algumas disciplinas, ele não é total, pois a maneira como o tempo e o ritmo da prática pedagógica é organizado está condicionada às regras de seleção dos conteúdos e ao sequenciamento. 
De acordo com Pires, Morais e Neves (2004), quando o compassamento é fraco, o formador pode acompanhar de forma mais apropriada os professores que necessitam de maior tempo para aprender. Além do mais, quando há a possibilidade de reorganizar o ritmo da prática pedagógica, tende-se a colaborar para uma democratização da aprendizagem.

Em síntese, as regras de sequenciamento se referem a uma progressão relativa ao que será transmitido. Elas implicarão em regras de compassamento, isto é, o ritmo/tempo esperado para aquisição dos conteúdos selecionados em um determinado espaço de tempo. O modo como acontece esse processo pode influenciar na mensagem de educação matemática comunicada na prática pedagógica, tal como se evidenciou nas categorias supracitadas. Dessa forma, ao entrelaçarmos as três categorias fica evidente que o tipo de educação ensinada aos professores participantes dessa formação pauta-se no paradigma do exercício.

A análise realizada dessas variações fornece indícios aos estudiosos interessados em investigar sobre formação continuada de professores e aproximação com diferentes formas de seleção, sequenciamento e compassamento das aulas no contexto do ProfMat. Portanto, esses resultados podem colaborar para mudanças na prática pedagógica e no modo como a mensagem de educação matemática é comunicada nesse curso de formação continuada. Transpondo esse contexto, configura um caminho reflexivo sobre como a mensagem de educar matematicamente que circula na referida formação pode deslocar-se para o contexto da educação básica.

\section{Conclusões}

De acordo com o objetivo proposto para este estudo, identificamos que o modo como o formador seleciona os conteúdos, organiza as aulas, modula o tempo e o ritmo esperado para que os professores aprendam está condicionado ao controle vertical exercido pela matriz nacional que regulamenta o curso, ao exame de qualificação, dentre outros fatores definidos nos documentos.

No quadro 1, a seguir, elaborado a partir dos dados analisados e discutidos neste estudo, apresentamos dois modos de educar matematicamente. O primeiro, predominante no ProfMat (representado pelo ponto na cor vermelha), está veiculado ao paradigma do exercício. O estudo de Silva (1996) aponta que o pressuposto do ensino tradicional é que, para ensinar, é preciso falar e, para aprender, é preciso ouvir. Já no segundo modo, cenários de investigação, ocorre o contrário. 
Quadro 1- Formas de educar matematicamente: Localização do ProfMat.

\begin{tabular}{|c|c|c|}
\hline $\begin{array}{l}\text { Formas de educar } \\
\text { matematicamente }\end{array}$ & Paradigma do exercício & Cenários para investigação \\
\hline Seleção do conteúdo & $\bullet$ & \\
\hline Sequenciamento & $\longrightarrow$ & \\
\hline Compassamento & $\bullet$ & \\
\hline
\end{tabular}

Fonte: Organizado pelos autores (2018), Legenda: ProfMat

Como seria se o polo ou até mesmo os formadores subvertessem os modos de educar matematicamente considerados legítimos para este contexto e investissem em cenários de investigação? Ao refletirmos sobre essa possibilidade, começamos a pensar que o professor poderia, por exemplo, participar de forma efetiva da seleção dos conteúdos, fazendo uso de critérios diferentes daqueles definidos nos documentos oficiais.

Finalmente, a análise realizada neste artigo sugere algumas compreensões sobre o funcionamento do ProfMat no seu interior, ou seja, no contexto de uma turma de um dos polos, bem como as formas de comunicação referentes a educar matematicamente cultivadas nesse programa. No entanto, este estudo realizado, em uma única turma de um polo, não têm a intenção de generalizar as informações, mas apresentar insights sobre como funciona esse programa por dentro, em um determinado período e contexto singular, entrevendo as práticas pedagógicas no ProfMat e suas mensagens sobre educar matematicamente.

\section{Referências}

ALRO, H.; SKOVSMOSE, O. Diálogo e aprendizagem em educação matemática. 2. ed. Belo Horizonte: Autêntica, 2010.

BERNSTEIN, B. Class, codes and control: the structuring of pedagogic discourse. New York: Routledge, 2003.

BERNSTEIN, B. Pedagogy, symbolic control and identity: theory, research, critique. New York: Rowman\& Littlefield, 2000. 
BRASIL. Coordenação de Aperfeiçoamento de Pessoal de Nível Superior (Capes). ProfMat: uma reflexão e alguns resultados. Rio de Janeiro, RJ, 2017.

BREDA, A.; LIMA, V. M. R. Estudio de caso sobre el anális didáctico realizado en un trabajo final de un máster para profesores de matemáticas en servicio. Journal of Research in Mathematics Education, v.5, n.1, p.74-103, fev. 2017.

CALDATTO, M. E; PAVANELLO R. M.; FIORENTINI, D. O PROFMAT e a formação do professor de matemática: uma análise curricular a partir de uma perspectiva processual e descentralizadora. Bolema, Rio Claro, v.30, n.56, p.906 - 925, dez. 2016.

CALDATTO, M. E; FIORENTINI, D; PAVANELLO R. M. Uma análise do projeto de formação profissional de professores privilegiada pelo PROFMAT. Zetetiké. Campinas, v.26, n.2, p.260281, dez. 2018.

CRESWELL, J. W. Projeto de pesquisa: métodos qualitativo, quantiativo e misto. Trad. Magda Lopes. 3. ed. Porto Alegre: ARTMED, 2010.

DAVID, M. M.; MOREIRA, P. C.; TOMAZ, V. S. Matemática escolar, matemática acadêmica e matemática do cotidiano: uma teia de relações sob investigação. Acta Scientiae, v.15, n.1, p.4260, jan./abr., 2013.

FARIAS, J. V.; VILELA, D. S. O curso de mestrado profissional em matemática em rede nacional à luz da teoria de Bourdieu: tensões entre matemática acadêmica e matemática escolar. Revista Educação PUC-Campinas. Campinas, v.22, n.1, p.109-129, jan./abr. 2017.

JARDILINO, J. R. L.; OLIVERI, A.M.R. Formação continuada de professores na região dos Inconfidentes: análise de um programa de formação - o PIBID. Revista UEMG, ano 17, n.24, p.43-69, dez. 2014.

JOHNSON, B.; CHRISTENSEN, L. Educational research: quantitative, qualitative, and mixed approaches. Thousand Oaks: Sage, 2012.

NACARATO, A. M. et al. Tendências das pesquisas brasileiras que têm o professor que ensina matemática como campo de estudo: uma síntese dos mapeamentos regionais. In: FIORENTINI, D; PASSOS, C. L. B.; LIMA, R. C. R. (orgs). Mapeamento da pesquisa acadêmica brasileira sobre o professor que ensina Matemática: período 2001-2012. Campinas: FE UNICAMP, p.319-350, 2016. Disponível em: https://www.fe.unicamp.br/pf-fe/pf/subportais/biblioteca/fev-2017/ebook-mapeamento-pesquisa-pem.pdf. Acesso em: 17 jun.2017.

OLIVEIRA, D. L. A. Prática profissional de professores do Distrito Federal a partir do curso GESTAR II Matemática. 2013. 141f. Dissertação (Mestrado em Educação) - Programa de PósGraduação em Educação da Faculdade de Educação, Universidade de Brasília, Brasília-DF, 2013. 
PIRES, D; MORAIS, A; NEVES, I. Desenvolvimento científico nos primeiros anos de escolaridade. Estudo de características sociológicas específicas da prática pedagógica. Revista de Educação, v.12, n.2, p.119-13, 2004.

SANTANA, F. C. M; GRILO, J. S. P; BARBOSA, J. C. Tensões entre os textos movidos da matemática escolar e o discurso pedagógico do PROFMAT. SEMINÁRIO INTERNACIONAL DE PESQUISA EM EDUCAÇÃO MATEMÁTICA, 7., 2018, Foz de Iguaçu. Anais [...]. Foz do Iguaçu, Paraná, p.1-12, 2018.

SILVA, M. R. G. Concepções didático-pedagógicas do professor-pesquisador em Matemática e seu funcionamento na sala de aula de Matemática. Bolema, ano 11, n.12, p.13-27, 1996.

SOUZA, E. N. Transposição didática: concepções de professores no contexto Gestar II. 2013. 77f. Dissertação (Mestrado em Educação) - Programa de Pós-Graduação em Educação em Ciências e Matemáticas, Instituto de Educação Matemática e Científica, Universidade Federal do Pará, Belém-PA, 2013.

VICENTE, J. P. A.; RESENDE, M. R. Profmat: um curso de formação de professores da educação básica? Revista Educação Pública. Cuiabá, v.25, n.58, p.201-220, jan./abr. 2016.

\section{AGRADECIMENTOS}

Agradecemos ao Colegiado do Programa ProfMat, aos formadores que ministraram as disciplinas eletivas e aos professores da educação básica. Ainda que não sejam responsáveis pelas posições adotadas neste artigo, também agradecemos a todos os membros do Grupo de Ensino de Ciências e Matemática (ENCIMA); Profa. Dra. Ana Virgínia de Almeida Luna; Profa. Dra. Andreia Maria Pereira de Oliveira; Profa. Dra. Marlova Estela Caldatto e Prof. Dr. Victor Augusto Giraldo, pelas valiosas interlocuções durante a produção deste estudo.

Recebido em março 2021.

Aprovado em junho 2021. 